\title{
openheart Sex-based inequalities in contemporary UK hospital management of stable chest pain
}

Mirvat Alasnag (D) , ${ }^{1}$ Nouf Alanazi ${ }^{2}$

To cite: Alasnag M, Alanazi N. Sex-based inequalities in contemporary UK hospital management of stable chest pain. Open Heart 2021;8:e001705. doi:10.1136/ openhrt-2021-001705

Accepted 17 May 2021

\section{SLinked}

- http://dx.doi.org/10.1136/ openhrt-2021-001597

Check for updates

(C) Author(s) (or their employer(s)) 2021. Re-use permitted under CC BY-NC. No commercial re-use. See rights and permissions. Published by BMJ.

${ }^{1}$ Cardiac Center, King Fahd Armed Forces Hospital, Jeddah, Saudi Arabia

${ }^{2}$ Cardiac Sciences Department, King Saud University, Riyadh, Riyadh Province, Saudi Arabia

Correspondence to Dr Mirvat Alasnag; mirvat@ jeddacath.com
The National Institute for Health and Care Excellence (NICE) in the UK is the designated body that recommends evidence-based guidelines to ensure quality care. It also identifies priority areas for improvement in the health system and care. In 2021, NICE updated its pathway for chest pain emphasising the role of cardiac CT (CCT) as a firstline investigation followed by non-invasive functional testing prompting invasive angiography when indicated. The updated version included a statement on the utility of fractional flow reserve (FFR)-CT in the evaluation of stable chest pain and its potential cost effectiveness based on data generated by the PLATFORM Quality of life and Economic Outcomes and FORECAST FFR-CT trials. ${ }^{1-4}$ The purpose of such a streamlined pathway is to eventually offer intensive risk modification for these stable patients and fast track those who require invasive angiography based on anatomic stratification by CCT or ischaemia documented by functional tests.

Morgan-Hughes et $a \tilde{l}$ provide us with a robust prospective analysis of real-world practices in eight centres in the UK between 2018 and 2020. This contemporary analysis evaluated 2301 women and 2326 men undergoing CCT wherein women were older and more likely to have normal coronary arteries. Functional testing was employed more commonly in men $(5 \%)$ than women $(4 \%)$ in the overall population; however, women were more likely to undergo functional testing if atheroma was detected for coronary artery disease Reporting and Data System (CAD-RADS) scores 4 and 5. Ultimately, fewer women underwent invasive angiography (8\%) compared with men $14 \%$. Similarly, women were less likely to undergo revascularisation; $4 \%$ compared with men $8 \%$ irrespective of the CAD-RADS Score.

The authors state that they were hoping CCT would level the ground for women. Previously, false positive results on functional imaging deterred physicians from referring women for invasive angiography. Both the SCOT-HEART (Scottish Computed Tomography of the Heart) and PROMISE (Prospective Multicenter Imaging Study for Evaluation of Chest Pain) studies report normal coronary arteries in $50 \%$ and $41 \%$ of women which is higher than that reported in men. ${ }^{2}{ }^{6}$ Data by Morgan-Hughes et al confirm these findings in real world practice whereby normal coronary arteries were detected in $46 \%$ of women. However, this may be an oversimplification of the evidence. Beyond semantics, angina is not interchangeable with ischaemia. Observational data from CLARIFY (ProspeCtive observational LongitudinAl RegIstry oF patients with stable coronary arterY disease) registry included more than 32000 patients with a median follow-up of 2 years. The event rate in those with stable angina was higher than those without angina irrespective of any underlying ischaemia. Both angina and ischaemia carried an insignificant higher risk, and ischaemia alone did not predict major adverse cardiovascular events (MACE) or all-cause mortality. Similarly, in the Heart and Soul Study of patients with established CAD and a median follow-up of 8.9 years, angina was associated with higher MACE rates which was independent of disease severity or ischaemia. ${ }^{78}$ Furthermore, subanalyses of the STICH (Surgical Treatment for Ischemic Heart Failure) and COURAGE (Clinical Outcomes Utilizing Revascularization and Aggressive Drug Evaluation) trials did not demonstrate a survival benefit when stratifying by treatment strategies, in particular revascularisation, or ischaemia burden. More recently, the unadjusted results of the ISCHEMIA trial demonstrated that the subset of patients who underwent percutaneous revascularisation had a reduction in stress-induced ischaemia and a lower event rate warranting further exploration. ${ }^{9}{ }^{10}$ More recent literature addresses ischaemia with non-obstructive coronary disease in which anatomy alone does not suffice to 

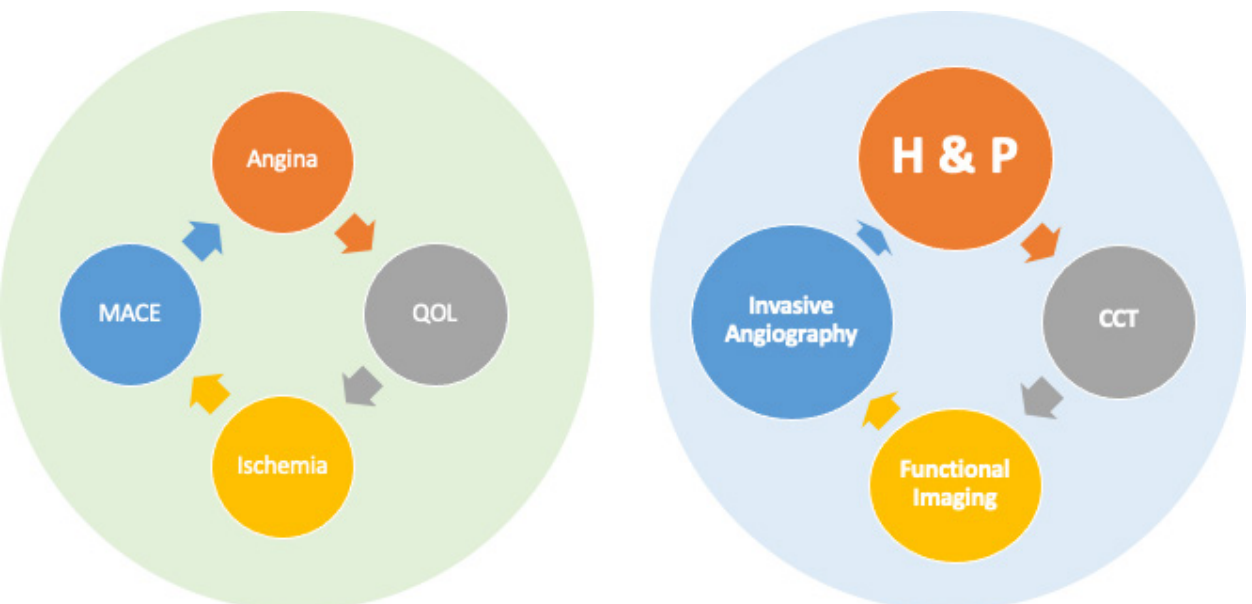

Figure 1 Central illustration: relationship between symptoms, ischaemia testing and outcomes.

diagnose conditions such microvascular dysfunction and further provocative testing is necessary. ${ }^{11}$

The NICE guidelines and the data presented in this UK population define anatomy followed by ischaemia in an already symptomatic population to determine the need for invasive angiography. As such, it is not surprising that fewer women are offered revascularisation based on this algorithm. The implications of curtailed invasive testing in symptomatic women are significant. Without a complete diagnosis of their angina, appropriate treatment will not be prescribed. There is ample evidence that women are less likely to receive statin therapy for atherosclerotic cardiovascular disease. The relationship between symptoms, ischaemia and anatomic testing and outcomes is complicated (figure 1). The UK data suggest that we may be denying women with angina other treatments as well since their angina and/or ischaemia remains under evaluated. In its quest for excellence, is the NICE algorithm a mere euphemism that falls short for women patients in the real world?

\section{Twitter Mirvat Alasnag @mirvatalasnag}

Contributors All authors contributed to this manuscript equally and acknowledge so.

Funding The authors have not declared a specific grant for this research from any funding agency in the public, commercial or not-for-profit sectors.

Competing interests None declared.

Patient consent for publication Not required.

Provenance and peer review Commissioned; internally peer reviewed.

Data availability statement There are no data in this work.

Open access This is an open access article distributed in accordance with the Creative Commons Attribution Non Commercial (CC BY-NC 4.0) license, which permits others to distribute, remix, adapt, build upon this work non-commercially, and license their derivative works on different terms, provided the original work is properly cited, appropriate credit is given, any changes made indicated, and the use is non-commercial. See: http://creativecommons.org/licenses/by-nc/4.0/.
ORCID iD

Mirvat Alasnag http://orcid.org/0000-0002-8714-0334

\section{REFERENCES}

1 NICE. National Institute for health and care excellence (NICE) guidance for the assessment and diagnosis of recent-onset chest pain of suspected cardiac origin (clinical guideline 95 (CG95)), 2010. Available: https://pathways.nice.org.uk/pathways/chest-pain [Accessed 17 Mar 2021].

2 Douglas PS, Pontone G, Hlatky MA. "Clinical outcomes of fractional flow reserve by computed tomographic angiography-guided diagnostic strategies vs. usual care in patients with suspected coronary artery disease: the prospective longitudinal trial of FFRCT: outcome and resource impacts study". Eur Heart J 2015:ehv444. doi:10.1093/eurheartj/ehv444

3 Hlatky MA, De Bruyne B, Pontone G, et al. Quality-Of-Life and economic outcomes of assessing fractional flow reserve with computed tomography angiography: platform. J Am Coll Cardiol 2015;66:2315-23.

4 Mahmoudi M, Nicholas Z, Nuttall J, et al. Fractional flow reserve derived from computed tomography coronary angiography in the assessment and management of stable chest pain: rationale and design of the forecast trial. Cardiovasc Revasc Med 2020;21:890-6.

5 Morgan-Hughes G, Williams MC, Loudon M, et al. Downstream testing after CT coronary angiography: time for a rethink? Open Heart 2021;8:e001597.

6 , Newby DE, Adamson PD, et al, SCOT-HEART Investigators. Coronary CT angiography and 5-year risk of myocardial infarction. $N$ Engl J Med 2018;379:924-33.

7 Steg PG, Greenlaw N, Tendera M, et al. Prevalence of anginal symptoms and myocardial ischemia and their effect on clinical outcomes in outpatients with stable coronary artery disease: data from the International observational clarify registry. JAMA Intern Med 2014;174:1651-9.

8 Beatty AL, Spertus JA, Whooley MA. Frequency of angina pectoris and secondary events in patients with stable coronary heart disease (from the heart and soul study). Am J Cardiol 2014;114:997-1002.

9 Panza JA, Velazquez EJ, She L, et al. Extent of coronary and myocardial disease and benefit from surgical revascularization in ischemic LV dysfunction [Corrected]. J Am Coll Cardiol 2014;64:553-61.

10 Rakisheva A, Marwan M, Achenbach S. The ischemia trial: implications for non-invasive imaging. Anatol J Cardiol 2020;24:2-6.

11 Herscovici R, Sedlak T, Wei J, et al. Ischemia and No Obstructive Coronary Artery Disease (INOCA): What Is the Risk? J Am Heart Assoc 2018;7:e008868. 